\title{
INFLUÊNCIA DOS REVESTIMENTOS COMESTÍVEIS NA PRESERVAÇÃO DA QUALIDADE PÓS- COLHEITA DE TOMATE DE MESA
}

Keren Railka Paiva Menezes, Guilherme Celestino de Souza Santos, Olganeth Moreira de Oliveira, Alex Guimarães Sanches, Carlos Alberto Martins Cordeiro, Antonio Rafael Gomes de Oliveira

Universidade Federal do Pará - UFPA, curso de Engenharia Agronômica, PA. E-mail: kerenrailka@hotmail.com

\section{RESUMO}

O tomate é uma das olerícolas de maior importância econômica e preferência de consumo.Entretanto, devido à alta perecibilidade deste fruto é fundamental o estudo de métodos para conservação pós-colheita do mesmo, por exemplo, o uso dos revestimentos comestíveis. Diante disso, o presente trabalho teve por objetivo avaliar os efeitos da aplicação de diferentes revestimentos comestíveis sobre a qualidade póscolheita de tomates de mesa armazenados sob temperatura ambiente. Os frutos foram revestidos com películas de fécula de mandioca, amido de milho, cloreto de cálcio e extrato de própolis nas concentrações de $3 \%$, e armazenados por 12 dias sob temperatura ambiente $\left(25 \pm 2^{\circ} \mathrm{C}\right.$ e $85 \pm 5 \%$ de U. R.). Foram avaliados a cada três dias de armazenamento quantoàperda de massa fresca, ao conteúdo de sólidos solúveis totais (SST), à acidez total titulável (ATT), ao pH, à relação SST/ATT e à aparência visual (firmeza, coloração da casca, qualidade geral e incidência de podridões).Em seguida, foi realizada uma análise de componentes principais (ACP). Houve efeito significativo ao nível de $1 \%$ de significância na interação dos fatores dias de armazenamento e revestimentos. De modo geral, os tratamentos com fécula de mandioca e amido de milho mantiveram as características fisiológicas e qualitativas que envolvem o amadurecimento dos tomates, sendo, portanto indicados como alternativas pós-colheita para prolongar a vida útil desses frutos quando mantidos em condição de temperatura ambiente de comercialização e consumo.

Palavras-chave: conservação; Solanum Lycopersicum; perecibilidade.

\section{THE INFLUENCE OF EDIBLE COATING IN PRESERVATION OF POST-HARVEST FRESH TOMATOES QUALITY}

\begin{abstract}
The tomato is one of the olerícolas of greater economic importance and preference of consumption. However, due to the high perishability of this fruit, it is fundamental to study methods for its post-harvest conservation, for example the use of edible coatings. The objective of this study was to evaluate the effects of the application of different edible coatings on the post-harvest quality of table tomatoes stored at room temperature. The fruits were coated with cassava starch, corn starch, calcium chloride and propolis extract at $3 \%$ concentrations and stored for 12 days at room temperature $\left(25 \pm 2{ }^{\circ} \mathrm{C}\right.$ and $\left.85 \pm 5 \% \mathrm{RH}\right)$. Total fresh solids content (TSS), total titratable acidity (ATT), pH, SST / ATT ratio and visual appearance (firmness, color bark, general quality and incidence of rot). Next, a principal component analysis (PCA) was performed. There was a significant effect at the $1 \%$ level of significance in the interaction of the days storage factors and coatings. In general, the treatments with cassava starch and corn starch maintained the physiological and qualitative characteristics that involve the maturing of the tomatoes and are therefore indicated as post-harvest alternatives to prolong the shelf life of these fruits when kept at room temperature conditions marketing and consumption.
\end{abstract}

Key -words: conservation; Lycopersicum esculentum Mill; perecibilidade.

\section{INTRODUÇÃO}

O tomate (Solanum Lycopersicum), é a hortaliça de maior preferência de consumo, estando presente diariamente da alimentação das pessoas (SCHWARZ et al., 2013). Esta ampla aceitação está associada às características nutricionais que apresenta, sendo um alimento rico em vitaminas $A$ e $C$, e de sais minerais como 
potássio e magnésio, importantes a nutrição humana (MELO et al., 2014).

O Brasil é o oitavo maior produtor de tomate, com uma produção superior a três milhões de toneladas em 2008, o que representa uma participação de $3,1 \%$ no total mundial (DIEESE, 2010). O Estado de São Paulo é o maior produtor do tomate para mesa, enquanto Goiás é o maior produtor do tomate industrial, sendo responsável por cerca de $80 \%$ da produção nacional total (SILVA NETO, 2014).

Entretanto, o tomate é um produto altamente perecível após a colheita dada a fragilidade dos seus tecidos e pela manutenção de sua atividade metabólica, demandando inúmeros esforços na sua conservação (FERRAZ et al., 2012).

Nesse sentido, torna-se importante o desenvolvimento de técnicas que possibilitem a manutenção da qualidade dos frutos por mais tempo. O emprego de biofilmes e coberturas comestíveis é uma alternativa tecnológica atraente para a conservação pós-colheita de frutas e hortaliças, pois possibilita a redução das trocas gasosas e da perda de águaentre alimento e ambiente, melhorando seu aspecto comercial (SANTOS et al., 2011). Além disso, o uso de revestimentos substituia utilização de embalagens que causam poluição quando descartadas no meio ambiente (SOUSA et al., 2010).

Os estudos sobre a conservação póscolheita do tomate já apontam várias pesquisas com o uso de revestimentos comestíveis (OLIVEIRA et al., 2011; EVANGELISTA et al., 2014; OLIVEIRA et al., 2015).Dentre os revestimentos utilizados destacam-se aqueles à base de polissacarídeos, pois apresentam baixa permeabilidade a gases (LUVIELMO; LAMAS, 2012). Filmes à base defécula de mandioca e de amido de milho são conhecidos por serem capazes de formar películas resistentes à perda de água e transparentes,tornando o fruto comercialmente atrativo devido ao seu bom aspecto e brilho intenso (SANTOS et al., 2011; JUNG; DEGENHARDT, 2016).

O cloreto de cálcio quando aplicado na pós-colheita dos frutos atua, principalmente, na preservação da firmeza, na redução da taxa respiratóriada produção de etileno, prolongando o período de vida útil do fruto (YAMAMOTO et al., 2011).

O extrato de própolis é um composto hidrofóbico que contribui para melhorar algumas propriedades de filmes de polímeros, tais como a barreira ao vapor de água que reduz a perda de massa por transpiração, que ocorre nos frutos durante o armazenamento (PASTOR et al., 2010). A própolis e seus extratos agem também como antimicrobianos naturais em substituição a fungicidas sintéticos utilizados no controle da conservação pós-colheita de produtos vegetais (KAMEYAMA et al., 2008).

Contudo, tais pesquisas utilizam apenas um único modelo de revestimento sob diferentes concentrações para avaliar os efeitos durante o armazenamento. Nesse contexto, o presente trabalho teve por objetivo avaliar o efeito da aplicação de diferentes revestimentos comestíveis a fim de determinar sua influência na preservação da qualidade do tomate de mesa armazenados sob condição de temperatura ambiente.

\section{MATERIAL E METODOS}

A presente pesquisa foi desenvolvida com tomates (Solanumlycopersicum) de mesa da cultivar TY, colhidos em propriedade agrícola que exploram a cultura em regime comercial de produção no município de Altamira-PA. Os frutos foram colhidos pela manhã em estádio de maturação fisiológico caracterizado pela tonalidade do epicarpo totalmente "verde". Com o intuito de padronizar o lote de frutos, estes foram selecionados quanto à uniformidade de tamanho, coloração da casca, ausência de danos mecânicos e acometidos por pragas e doenças.

Os tomates foram acondicionados em caixas térmicas e transportados até o Laboratório de Química da Universidade Federal do Pará, Campus Altamira (PA), onde foram primeiramente submetidos à lavagem em água corrente para a retirada das sujidades oriundas do campo. Em seguida, os frutos foram sanitizados utilizando solução de hipoclorito de sódio a $200 \mathrm{mg}^{-1} \mathrm{~L}^{-1}$ durante $5 \mathrm{~min}$, e dispostos em bancadas para secagem em condição de temperatura ambiente.

O preparo dos revestimentos foi realizado pesando-se $30 \mathrm{~g}$ de fécula de mandioca, $30 \mathrm{~g}$ de amido de milho, $30 \mathrm{~g}$ de cloreto de cálcio, com posterior diluição em $1 \mathrm{~L}$ de água destilada chegando à concentração de $(3 \% \mathrm{p} / \mathrm{v})$, em cada tratamento. A suspensão de fécula de mandioca e amido de milho foi aquecida a $70^{\circ} \mathrm{C}$ até a completa geleificação com posterior repouso em temperatura ambiente até o resfriamento. 
O revestimento com extrato de própolis foi preparado diluindo-se $30 \mathrm{~mL}$ da solução aquosa em $1 \mathrm{~L}$ de água destilada (3 \% v/v) em então pulverizados sobre os frutos de maneira uniforme.

$\mathrm{Na}$ aplicação dos revestimentos, os frutos foram imersos, um a um, nas suspensões por $3 \mathrm{~min}$ e dispostos em bandejas para a drenagem do excesso de revestimento. Um lote de frutos não foi submetido ao tratamento com revestimentos, configurando $o$ tratamento controle.

Após a aplicação dos revestimentos, os frutos foram armazenados sob temperatura ambiente ( $25 \pm 2^{\circ} \mathrm{C}$ e $85 \pm 5 \%$ de U. R.), simulando as condições de comercialização nos pontos de venda a varejo por um período de 12 dias com avaliações sobre as variáveis físico-químicas e sensoriais realizadas a cada três dias.

Perda de massa fresca (PMF) determinada com auxílio de balança semianalítica (TECNAL, modelo CL2), calculando-se a diferença obtida entre os valores da massa inicial (MI) e final (MF) dos frutos em cada dia de avaliação através da seguinte equação: $P M F=(M I$

- MF) x 100.0s resultados foram expressos em porcentagem (\%).

O teor de sólidos solúveis totais (SST) foi obtido pela leitura direta em refratômetro digital portátil (ATAGO, modelo PR-101) utilizando $10 \mathrm{~g}$ da amostra macerada conforme recomendações da AOAC (2012) e os resultados expressos em ${ }^{\circ}$ Brix.

A acidez total titulável (ATT) foi determinada conforme a metodologia descrita pelo AOAC (2012), onde $10 \mathrm{~g}$ de polpa de tomate foram homogeneizados com $100 \mathrm{~mL}$ de água destilada. Àsolução resultante foi adicionada 3gotas de fenolftaleína a $1 \%(\mathrm{~m} / \mathrm{v})$ e, em seguida, titulada com $\mathrm{NaOH}$ a 0,1M até atingir coloração rósea. Os resultados foram expressos em (\%) de ácido cítrico/ $100 \mathrm{~g}$ de polpa.

$\mathrm{O} \mathrm{pH}$ foi obtido por leitura direta da polpa triturada em pHmetro digital (TECNAL, modelo MPA 2010), devidamente calibrado em solução tampão 4,0 e 7,0 conforme o AOAC (2012).

A relação SST/ATT foi determinada a partir da divisão entre os valores de SST e de ATT.

A avaliação sensorial foi realizada pelo método descritivo através de uma equipe de 7 pessoas treinadas que atribuíram notas em uma escala hedônica de cinco pontos as amostras de cada tratamento (Quadro 1) conforme o proposto por AOAC (2012).

Tabela 1. Avaliação sensorial sobre os atributos firmeza, coloração da casca, odor, qualidade geral e incidência de podridões em frutos de diferentes cultivares do tomate de mesa.

\begin{tabular}{ll}
\hline \multicolumn{1}{c}{ Firmeza } & \multicolumn{1}{c}{ Coloração da casca } \\
\hline 5. Firme & 5. Verde \\
4. Ligeiramente firme & 4. Verde com traços amarelos \\
3. Moderadamente firme & 3. Amarelo \\
2. Pouco mole, macio & 2. Amarelo com traços alaranjados \\
1. Mole, macio & \multicolumn{1}{c}{ 1. Vermelho } \\
\hline \multicolumn{1}{c}{ Qualidade geral } & \multicolumn{1}{c}{ Incidência de podridões } \\
\hline 5. Excelente, livre de defeitos & 5. 0\% de podridão \\
4. Boa, pequenos defeitos & 4. Até $5 \%$ dos frutos afetados \\
3. Defeitos médios, não limita o consumo & 3. Até $25 \%$ dos frutos afetados \\
2. Defeitos excessivos, consumo limitado & 2. Até $50 \%$ dos frutos afetados \\
1. Podre, não utilizável & 1. Mais de $50 \%$ dos frutos afetados \\
\hline
\end{tabular}

Fonte: AOAC (2012).

O experimento foi conduzido em um delineamento inteiramente casualizado sob um arranjo fatorial $5 \times 5$, sendo fatores o período de armazenamento $(0 ; 3 ; 6 ; 9$ e 12 dias) e os tratamentos (controle, fécula de mandioca a $3 \%$, amido de milho a $3 \%$, cloreto de cálcio a $3 \%$ e extrato de própolis a 3\%). Cada tratamento foi composto por quatro repetições e a parcela experimental constituída por dois frutos.

Os dados foram submetidos à análise de variância (ANOVA) pelo teste $\mathrm{F}$ e a comparação das médias pelo teste de Tukey ao nível de $5 \%$ de 
significância através do software Assistat 7.7 versão beta (SILVA; AZEVEDO, 2016).Para a análise multivariada, dados de todas as variáveis foram padronizados utilizando-se o programa Excel (2010) e submetidos à análise de componentes principais (ACP), utilizando uma matriz de correlação como auxílio do Software STATISTIC 7.0 (STATSOFT, 2004).

\section{RESULTADOS E DISCUSSÃO}

O resumo da ANOVA apresentado na Tabela 2 mostra que houve efeito significativo ao nível de $1 \%(p<0,01)$ para todas as características físico-químicas avaliadas na interação dos fatores dias de armazenamento e tratamentos.

Tabela 2. Resumo da análise de variância (ANOVA) pelo teste $F$ sobre as variáveis físico-químicas de: perda de massa fresca (PMF \%), sólidos solúveis totais (SST ${ }^{\circ}$ Brix), acidez total titulável (ATT \% ácido cítrico), pH e relação (SST/ATT), em função dos dias de armazenamento, dos tratamentos utilizados e da interação entre esses fatores.

\begin{tabular}{ccccccc}
\hline \multirow{2}{*}{ Fontes de variação } & \multicolumn{7}{c}{ Quadro de análise } \\
\cline { 3 - 7 } & GL & PMF & SST & ATT & pH & SST/ATT \\
\cline { 1 - 4 } Dias de armazenamento & 4 & $162,88^{* *}$ & $53,85^{* *}$ & $150,46^{* *}$ & $135,23^{* *}$ & $286,26^{* *}$ \\
Revestimentos & 4 & $84,80^{* *}$ & $2,50^{* *}$ & $114,52^{* *}$ & $65,14^{* *}$ & $107,27^{* *}$ \\
Int. Dias x Revestimentos & 16 & $6,80^{* *}$ & $34,99^{* *}$ & $49,11^{* *}$ & $42,47^{* *}$ & $30,47^{* *}$ \\
Tratamento & 24 & $291,82^{* *}$ & $113,72^{* *}$ & $243,57^{* *}$ & $265,04^{* *}$ & $51,73^{* *}$ \\
Resíduo & 75 & 0,016 & 0,016 & 0,08 & 0,07 & 0,08 \\
\hline CV $(\%)=$ & & 3,47 & 2,51 & 2,66 & 0,22 & 0,27 \\
\hline
\end{tabular}

${ }^{* *}$ significativo ao nível de $1 \%$ de probabilidade $(\mathrm{p}<0.01)$; ${ }^{*}$ significativo ao nível de $5 \%$ de probabilidade $(0.01=<\mathrm{p}$ $<0.05)$; ns = não significativo $(p>=0.05)$.

A perda de massa fresca apresentou-se crescente em todos os tratamentos, influenciada principalmente pelo processo de transpiração com perda estimada de até $4,15 \%$ ao final do período de armazenamento para frutos controle (Figura 1). Esse percentual é similar ao verificado por Chiumarelli e Ferreira (2006) que durante o armazenamento de tomates de mesa da cv. Débora revestidos com ceras comerciais notaram perdas em torno $4,10 \%$ durante 12 dias de armazenamento a temperatura ambiente.

Figura 1. Perda de massa fresca (\%) em tomates de mesa revestidos com diferentes revestimentos e armazenados à temperatura ambiente $\left(25 \pm 2^{\circ} \mathrm{C}\right.$ e $85 \pm 5 \%$ de U. R.) por 12 dias. Letras minúsculas (dias de armazenamento) e maiúsculas (tratamentos) não diferem entre si pelo teste de Tukey ao nível de $5 \%$ de probabilidade.

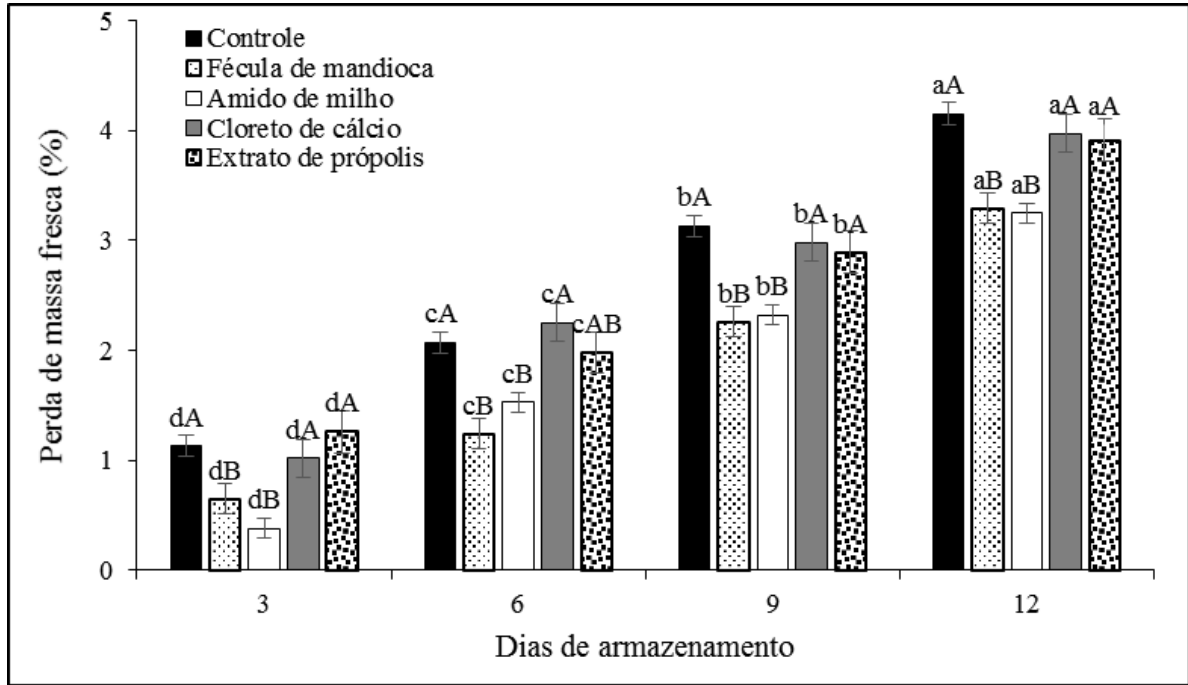


Ainda de acordo com a Figura 1, nota-se que apesar do acréscimo gradual da perda de massa, os frutos revestidos com fécula de mandioca e amido de milho, apresentaram os menores percentuais durante todo o período de armazenamento com perdas inferiores a 3,15\% ao final de 12 dias, não diferindo entre si $(p<0,05)$.

O revestimento à base de fécula de mandioca a $2 \%$ e $4 \%$ quando aplicado em espigas de minimilho (QUEIROZ et al., 2010) e em tomates de mesa cv. SM'16 (OLIVEIRA et al., 2011), assim como o revestimento à base de amido de milho a $3 \%$ em tomates cereja (EVANGELISTA et al., 2014) também mostraramse eficientes na reduçãoda perda de massa fresca ao longo do período de armazenamento com relação controle.

As películas formadas à base de carboidratos permitem as trocas gasosas entre 0 vegetal e o meio externo através de um quociente respiratório menor (LUVIELMO; LAMAS, 2012). Isso explica a menor perda de massa fresca obtidas nos frutos revestidos com fécula de mandioca e amido de milho uma vez que se restringiu as trocas gasosas, reduzindo a taxa respiratória e a transpiração que favorecem a perda de água (Figura 1).

Os tratamentos com cloreto de cálcio e extrato de própolis por não formarem uma película sobre os frutos apresentaram maior porcentagem de perda de massa fresca motivada pela alta taxa de transpiração, não diferindo em relação aos frutos do tratamento controle embora apresentassem menores percentuais durante $o$ armazenamento (Figura 1).

Analisando a Figura 2, observa-se que os teores de sólidos solúveis totais (SST) apresentaram uma tendência de aumento até o nono dia de avaliação nos frutos dos tratamentos controle $\left(6,13^{\circ} \mathrm{Brix}\right)$, cloreto de cálcio $\left(6,18^{\circ} \mathrm{Brix}\right)$ e extrato de própolis $\left(6,21^{\circ} \mathrm{Brix}\right)$ com posterior redução no último dia de avaliação, médias de 4,85; 5,07 e $5,14{ }^{\circ}$ Brix, respectivamente. Nos frutos revestidos com fécula de mandioca e amido de milho,foi observado um aumento no teor de SST durante todo o período de armazenamento passando de $4,10^{\circ} \mathrm{Brix}$ no dia zero para $6,25{ }^{\circ}$ Brix aos 12 dias de armazenamento, respectivamente.

Figura 2. Conteúdo de sólidos solúveis totais ( $\left.{ }^{\circ} \mathrm{Brix}\right)$ em tomates de mesa revestidos com diferentes revestimentos e armazenados à temperatura ambiente $\left(25 \pm 2^{\circ} \mathrm{C}\right.$ e $85 \pm 5 \%$ de $\mathrm{U}$. R) por 12 dias. Letras minúsculas (dias de armazenamento) e maiúsculas (tratamentos) não diferem entre si pelo teste de Tukey ao nível de $5 \%$ de probabilidade.

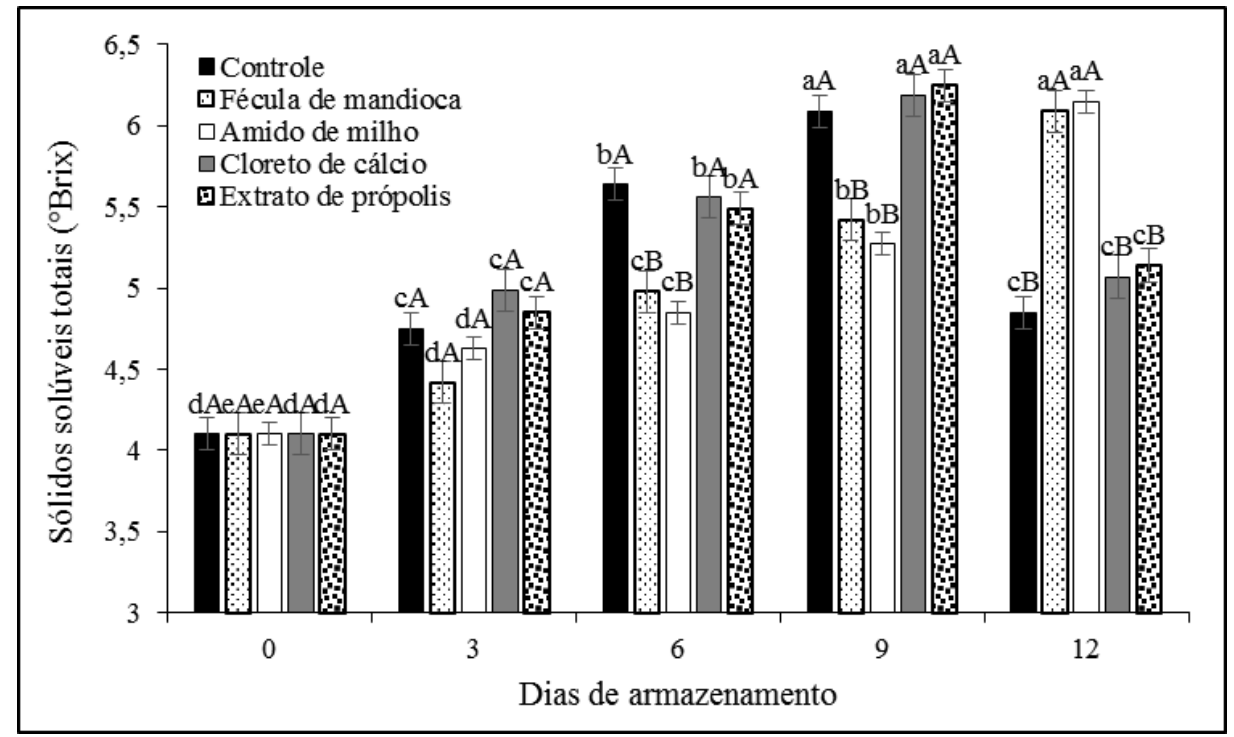

Os tomates revestidos com fécula de mandioca e amido de milho apresentaram teores de SST similares durante o período de avaliação, indicando que ambos conseguiram retardar o processo de maturação dos frutos já que se apresentavam menos "doces", isto é, em um estádio mais verde dado ao menor acúmulo de açúcares na polpa ao final de 12 dias com médias de 6,09 e $6,15^{\circ} \mathrm{Brix}$, respectivamente (Figura 2 ). 
Esses resultados corroboram com os verificados por Santos et al. (2011), Barbosa et al. (2012) e por Moreira et al. (2017), que além de não observarem diferenças significativas entre os revestimentos fécula de mandioca e amido de milho, constataram menor consumo de açúcares na polpa de mangas, muricis e pimentões, respectivamente, indicando eficiência no controle do processo de maturação que hidrolisa o amido em açúcar.
Os teores de acidez presente na polpa dos tomates reduziram com o tempo de armazenamento passando de 0,35 \% de ácido cítrico no dia zero para menos de 0,19\% de ácido cítrico ao final de 12 dias de armazenamentonos frutos controle e nos tratados com cloreto de cálcio (Figura 3).

Figura 3. Acidez total titulável (\% ácido cítrico/100g de polpa) em tomates de mesa revestidos com diferentes revestimentos e armazenados à temperatura ambiente $\left(25 \pm 2{ }^{\circ} \mathrm{C}\right.$ e $85 \pm 5 \%$ de U. R) por 12 dias. Letras minúsculas (dias de armazenamento) e maiúsculas (tratamentos) não diferem entre si pelo teste de Tukey ao nível de $5 \%$ de probabilidade.

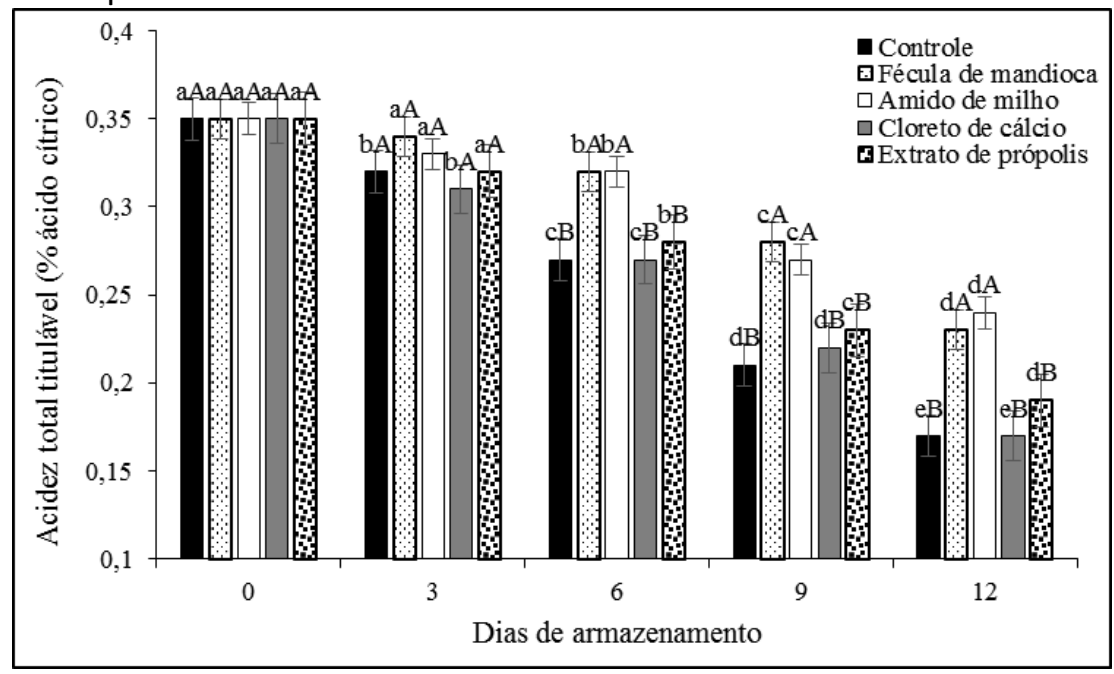

Esses resultados são inferiores aos obtidos por Ferreira et al. (2010) que trabalhando com os tomates de mesa cv. Raísa (convencional) e cv. Santa Clara (orgânico), observaram teores de acidez variando de 0,58 a 0,21 e de 0,49 a $0,24 \%$ de ácido cítrico, respectivamente, durante 12 dias de armazenamento refrigerado. Costa et al. (2012), encontraram variações de acidez entre 0,48 a $0,41 \%$ de ácido cítrico na polpa do tomate de mesa cv. Seminis durante 12 dias de armazenamento, sob refrigeração a $13 \pm 1^{\circ} \mathrm{C}$. Nesse contexto, pode-se afirmar que a cultivar TY como tomate de mesa apresenta boas características para consumo in natura uma vez que apresenta uma baixa constituição de ácidos orgânicos em sua polpa se comparada a outras cultivares da mesma espécie.

Chitarra e Chitarra (2005), explicam que a quantidade de ácidos orgânicos tende a reduzir em função do seu uso como substrato no processo respiratório ou da conversão dos ácidos orgânicos em açúcares durante a maturação dos frutos.
Analisando a Figura 3, observa-se que os revestimentos formados sob os frutos tratados com fécula de mandioca e amido de milho reduziram a atividade respiratória dos mesmos, conservando mais o teor ácidos orgânicos na polpa, retardando sua senescência se comparado aos tratamentos controle, cloreto de cálcio e extrato de própolis. Os mesmos apresentaram reduções expressivas logo após o terceiro dia de armazenamento dada a baixa capacidade de controlar a maturação dos frutos observando um maior consumo dos ácidos orgânicos para manter a respiração.

Oliveira et al. (2015) e Evangelista et al. (2014) também notaram redução nos teores de acidez titulável na polpa de tomates durante 12 dias de avaliação, no entanto observaram que os frutos revestidos com fécula de mandioca e amido de milho, respectivamente, apresentaram menor degradação dos ácidos orgânicos durante o armazenamento, similar ao observado neste trabalho.

Segundo a AOAC (2012), o pH de tomates varia de 3,50 a 4,70 valores estes semelhantes 
aos encontrados nesta pesquisa cujos valores médios ficaram entre 4,45 a 4,66 durante 0 armazenamento dos frutos controle (Figura 4). Resultados similares foram obtidos em tomates de mesa do grupo italiano como os verificados por Ferreira et al. (2010), que trabalhando com a cv. Raísa obtiveram valores oscilando entre 4,24 a 4,52 e por Rosa et al. (2011), que ao avaliarem a cv. Chico Grande observaram valores variando entre 4,46 a 4,60.

Figura 4. Valor de $\mathrm{pH}$ em tomates de mesa revestidos com diferentes revestimentos e armazenados à temperatura ambiente $\left(25 \pm 2^{\circ} \mathrm{C}\right.$ e $85 \pm 5 \%$ de U. R) por 12 dias. Letras minúsculas (dias de armazenamento) e maiúsculas (tratamentos) não diferem entre si pelo teste de Tukey ao nível de $5 \%$ de probabilidade.

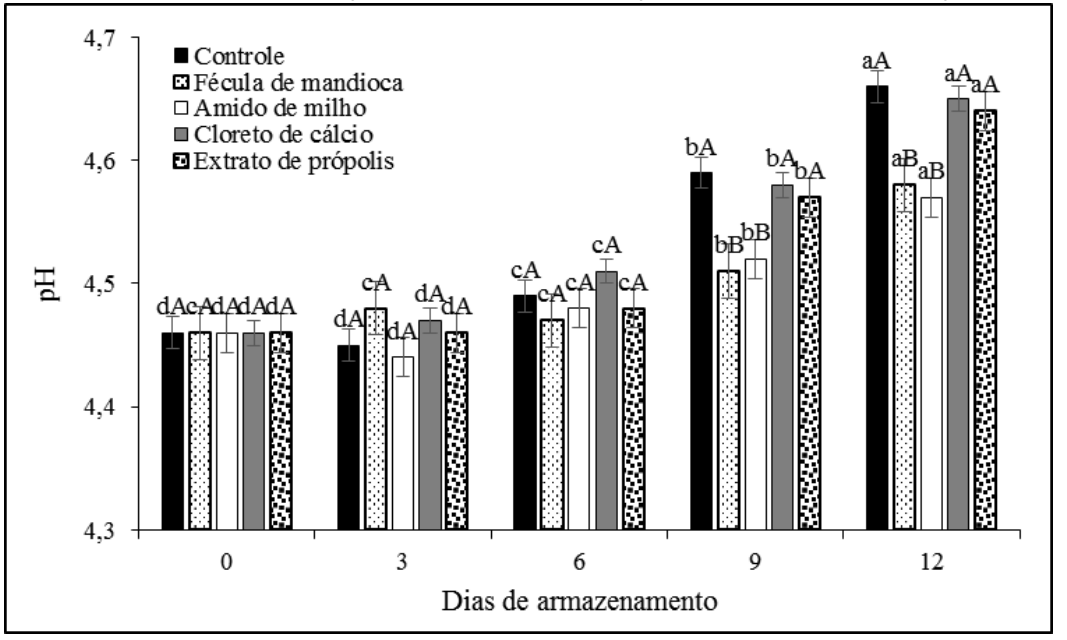

De acordo com a Figura 4, observa-se que os valores depHapresentaram-se crescentes em todos os tratamentos à medida que houve 0 avanço no período de armazenamento dos frutos com diferença significativa $(p<0,05)$ entre si somente após o sexto dia de avaliação, onde os frutos tratados com fécula de mandioca e amido de milho apresentam os menores valores até o fim do armazenamento.

O uso de revestimentos à base de fécula de mandioca e de amido de milho também foram eficientes em retardar o aumento do $\mathrm{pH}$ durante o armazenamento de bananas cv. Maçã (SILVA et al., 2015) e em goiabas cv. Paluma (LUNGUINHO et al., 2014), respectivamente.

A relação entre sólidos solúveis totais e acidez total titulável (SST/ATT) determinada de ratio é o parâmetro mais importante dentre os analisados na pós-colheita, pois determina até que ponto $\mathrm{o}$ produto se encontra com características organolépticas ideias para consumo através do equilíbrio entre os teores de açucares e de ácidos na polpa dos frutos e hortaliças (CHITARRA; CHITARRA, 2005).

Observa-se através da Figura 5 , que os valores de relação (SST/ATT) apresentaram aumento até o nono dia com média de 14,20 nos frutos dos tratamentos controle, cloreto de cálcio e extrato de própolis. Já nos frutos revestidos com fécula de mandioca e amido de milho esse aumento é verificado durante todo o período de armazenamento, com média de 14,50. 
Figura 5. Relação (SST/ATT) em tomates de mesa revestidos com diferentes revestimentos e armazenados à temperatura ambiente $\left(25 \pm 2{ }^{\circ} \mathrm{C}\right.$ e $85 \pm 5 \%$ de U. R) por 12 dias. Letras minúsculas (dias de armazenamento) e maiúsculas (tratamentos) não diferem entre si pelo teste de Tukey ao nível de $5 \%$ de probabilidade.

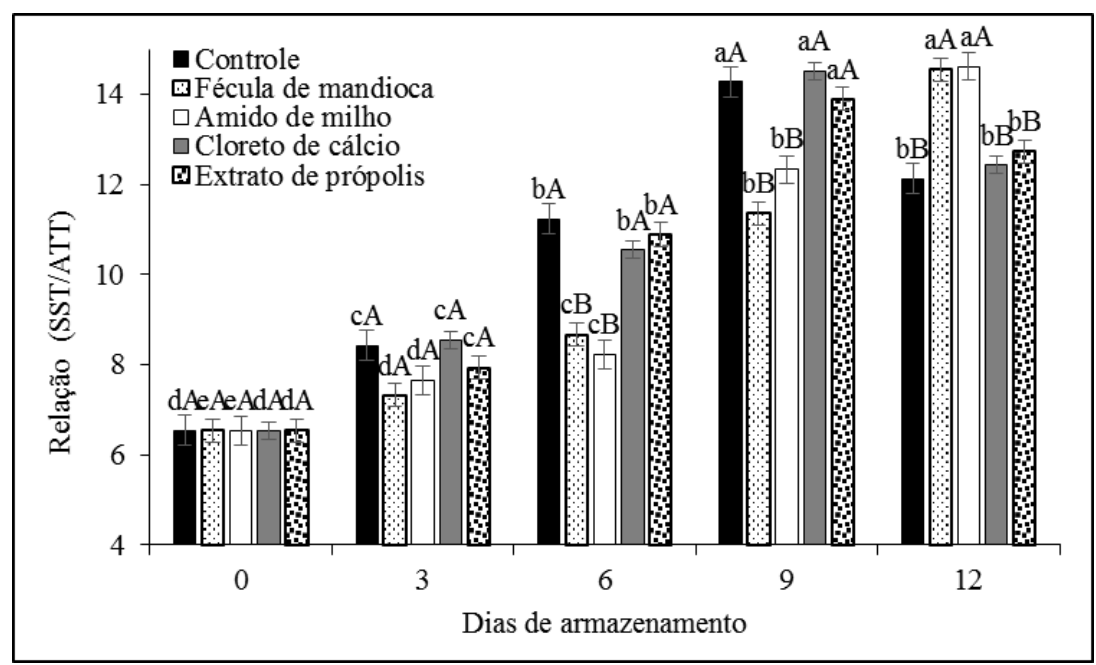

Kader e Rolle (2004) explicam que o aumento na relação SST/ATT é decorrente do processo de maturação dos frutos que concentra os açúcares na polpa dos frutos (SST) e reduz os ácidos orgânicos (ATT) em função do metabolismo respiratório que os consomem para manter a vida útil. Já a redução nesta relação indica o consumo dos açúcares (SS) como substrato energético levando a perda de sabor característico e início de senescência.

Ante o exposto, a redução observada nos tratamentos após nove dias de armazenamento configura-se como um indicativo de perda de qualidade uma vez que o sabor passou a ser afetado em decorrência do amadurecimento avançado. Nos frutos tratados com fécula de mandioca e amido de milho houve um maior controle das trocas gasosas com o meio,promovendo uma maturação menos acelerada preservando desta forma um balanço entre açúcares e ácidos orgânicos por até 12 dias de armazenamento (Figura 5).

A Tabela 3 apresenta o resumo da ANOVA sobre as variáveis sensoriais, evidenciando que houve efeito significativo ao nível de $1 \%(p<0,01)$ na interação entre os fatores dias de armazenamento e revestimentos para todas as características avaliadas.

Tabela 3. Resumo da análise de variância (ANOVA) pelo teste $F$ sobre as variáveis sensoriais de: firmeza (FMZ), coloração da casca (CC), qualidade geral (QG) e incidência de podridões (IP) em função dos dias de armazenamento, dos tratamentos utilizados e da interação entre esses fatores.

\begin{tabular}{cccccc}
\hline \multirow{2}{*}{ Fontes de variação } & \multicolumn{5}{c}{ Quadro de análise } \\
\cline { 3 - 6 } & $\mathrm{GL}$ & $\mathrm{FMZ}$ & $\mathrm{CC}$ & $\mathrm{QG}$ & $\mathrm{IP}$ \\
Dias de armazenamento & 4 & $139,06^{* *}$ & $197,58^{* *}$ & $171,76^{* *}$ & $39,65^{* *}$ \\
Revestimentos & 4 & $18,81^{* *}$ & $25,29^{* *}$ & $10,45^{* *}$ & $5,57^{* *}$ \\
Int. Dias x Revestimentos & 16 & $3,98^{* *}$ & $5,32^{* *}$ & $4,31^{* *}$ & $2,54^{* *}$ \\
Tratamento & 24 & $28,97^{* *}$ & $40,69^{* *}$ & $33,12^{* *}$ & $9,23^{* *}$ \\
Resíduo & 75 & 0,09 & 0,09 & 0,05 & 0,04 \\
\hline CV $(\%)=$ & & 4,38 & 3,24 & 5,13 & 4,23 \\
\hline
\end{tabular}

** significativo ao nível de $1 \%$ de probabilidade $(\mathrm{p}<0.01) ; *$ significativo ao nível de $5 \%$ de probabilidade $(0.01=<p$ $<0.05)$; ns = não significativo $(p>=0.05)$.

A perda de firmeza durante o amadurecimento é ocasionada pela degradação da parede celular e pela perda de umidade (SARMENTO et al., 2015). Analisando a Figura 6, observa-se que a firmeza decresceu significativamente ao longo do tempo de armazenamento e entre os tratamentos, influenciada principalmente pela perda de água e dos processos metabólicos que induzem o amadurecimento como maior atividade 
respiratória, síntese de etileno e atuação de enzimas que degradam a parede celular.

Figura 6. Valores de firmeza de tomates de mesa revestidos com diferentes revestimentos e armazenados à temperatura ambiente $\left(25 \pm 2^{\circ} \mathrm{C}\right.$ e $85 \pm 5 \%$ de U. R) por 12 dias. Letras minúsculas (dias de armazenamento) e maiúsculas (tratamentos) não diferem entre si pelo teste de Tukey ao nível de $5 \%$ de probabilidade.

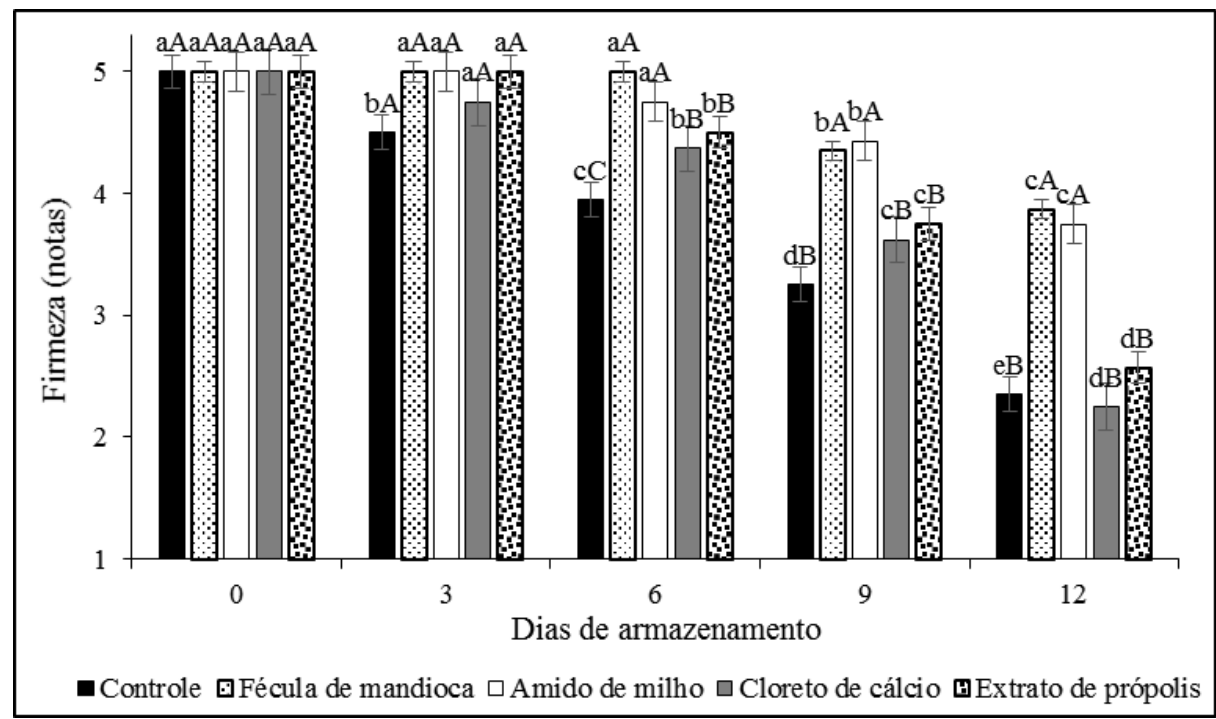

Observa-se na Figura 6 que a perda de firmeza foi mais acentuada após o terceiro dia de armazenamento em todos os tratamentos, exceto nos frutos revestidos com fécula de mandioca e amido de milho que se apresentarammais firmes ao longo de todo o armazenamento com nota média de 3,85 e 3,75 , respectivamente. Ao final do décimo segundo dia de armazenamento os frutos caracterizavam-se como (ligeiramente firmes), não diferindo entre si e sendo estatisticamente superiores aos demais tratamentos cuja nota média para o mesmo período ficou em torno de 2,50 (pouco mole, macio).

Em um comparativo entre o revestimento de fécula de mandioca e amido de milho Barbosa et al. (2012), também não encontram diferença significativa $(p<0,05)$ sobre a firmeza de muricis armazenados sob condição ambiente por oito dias, no entanto ambos foram superiores aos frutos do grupo controle. De maneira similar Santos et al. (2011) avaliando a influência dos biofilmes de fécula de mandioca e amido de milho na qualidade pós-colheita de mangas 'Tommy Atkins', não verificaram diferenças entre si $(p<0,05)$ e que ambos mantiveram a firmeza dos frutos por um período de 21dias de armazenamento.

A cor é o atributo de qualidade mais atrativo e está intimamente relacionada com a aparência, o teor de açúcares, a acidez, o pH, a textura, o sabor e a suculência (FERREIRA et al., 2010). No tomate, a coloração está relacionada com o estádio de maturação, sendo um fator de grande influência na vida pós-colheita desse fruto já que é um dos principais auxílios de escolha por parte do consumidor.

De acordo com a Figura 7, observase que a coloração da películasofreu alterações conforme os dias de armazenamento, passando de verde $(5,0)$ para amarelo com traços alaranjados $(2,0)$ decorrente do processo de amadurecimento, onde ocorre a degradação da clorofila levando a perda da cor verde e a síntese de pigmentos como os carotenóides que conferem a cor amarela, laranjada e vermelha. 
Figura 7. Coloração da película em tomates de mesa revestidos com diferentes revestimentos e armazenados à temperatura ambiente $\left(25 \pm 2^{\circ} \mathrm{C}\right.$ e $85 \pm 5 \%$ de U. R) por 12 dias. Letras minúsculas (dias de armazenamento) e maiúsculas (tratamentos) não diferem entre si pelo teste de Tukey ao nível de $5 \%$ de probabilidade.

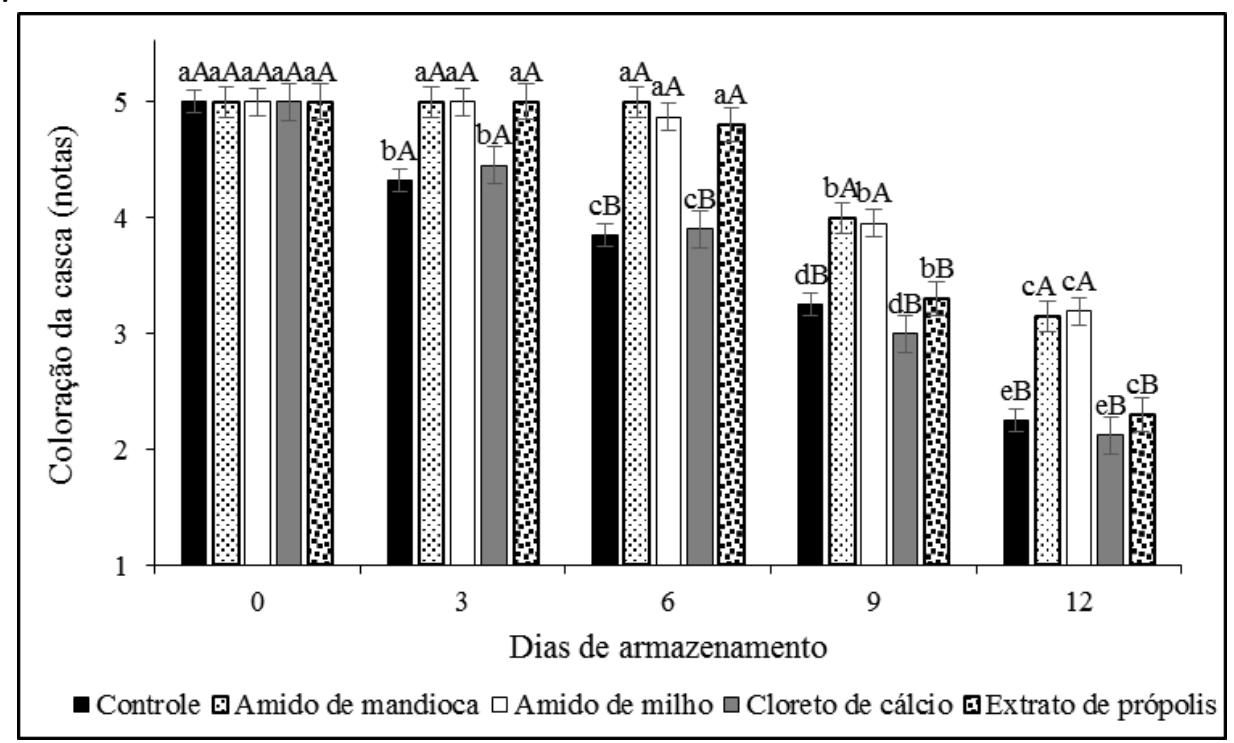

Aos três dias de armazenamento, as alterações na coloração da casca significativas a nível de $5 \%$ de probabilidade são observadas nos frutos controle e nostratados com cloreto de cálcio. Nos frutos revestidos com fécula de mandioca, amido de milho e extrato de própolis não se observa diferenças significativas entre si $(p<0,05)$ até o sexto dia de armazenamento revelando poucas alterações na coloração da casca dos frutos caracterizando-os com nota média de 4,85 (verde com traços amarelos) (Figura 7).

Após seis dias de armazenamento somente os frutos revestidos com fécula de mandioca e amido de milho apresentaram retardo na degradação da clorofila sendo caracterizados com nota média de 3,0 (amarelo) aos 12 dias de análise. Para o mesmo período não se observou diferenças significativas entre os frutos dos tratamentos controle, cloreto de cálcio e extrato de própolis cuja coloração da casca foi caracterizada como próximo ao vermelho (Figura 7).

A fécula de mandioca e o amido de milho retardaram as mudanças na coloração da casca de mangas (VIEIRA et al., 2009) e de bananas (MONTIBELLER et al., 2016), respectivamente, quando armazenadas em condição de temperatura ambiente. Moreira et al. (2017), observaram que os biofilmes de fécula de mandioca e amido de milho na concentração de $3 \%$ não apresentaram diferenças entre si e foram eficientes em retardar a degradação da clorofila em pimentões, até $o$ nono dia de armazenamento, corroborando com os observados neste trabalho.

A qualidade de um produto está associada a sua aparência externa sendo considerado o fator de maior importância do ponto de vista de comercialização (CHITARRA; CHITARRA, 2005). A aparência externa é avaliada por diferentes atributos tais como grau de frescor, tamanho, forma, cor, higiene, maturidade e ausência de defeitos (SOUZA et al., 2009), sendo um fator determinante na escolha dos frutos pelos consumidores (MELO et al., 2016).

Neste trabalho,os avaliadores não observaram alterações significativas $(p<0,05)$ na qualidade geral dos frutos controle e tratados até o sexto dia de armazenamento. A partir do nono dia até o fim do período de avaliação somente aos frutos revestidos com fécula de mandioca e amido de milho foram atribuídas as maiores notas de qualidade $(4,0$ - boa, com pequenos defeitos). Nos demais tratamentos, a qualidade foi classificada com nota média de 3,0 (defeitos médios, não limita o consumo) (Figura 8). 
Figura 8. Qualidade geral em tomates de mesa revestidos com diferentes revestimentos e armazenados à temperatura ambiente $\left(25 \pm 2^{\circ} \mathrm{C}\right.$ e $85 \pm 5 \%$ de U. R) por 12 dias. Letras minúsculas (dias de armazenamento) e maiúsculas (tratamentos) não diferem entre si pelo teste de Tukey ao nível de $5 \%$ de probabilidade.

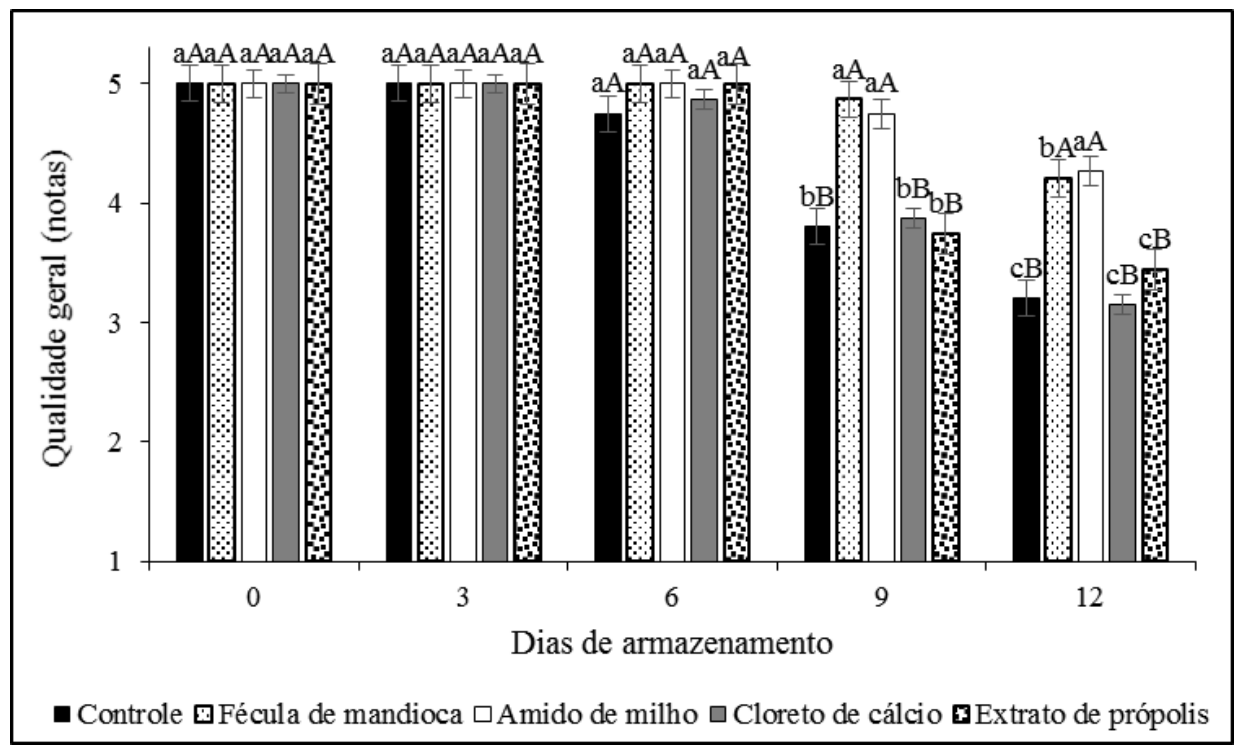

De acordo com Assis e Brito (2014), a película formada sob os frutos além de reduzir as taxas de transpiração e a respiração conferem um aspecto brilhoso, melhorando o aspecto comercial e, consequentemente, de qualidade, justificando os resultados obtidos quando utilizado a fécula de mandioca e o amido de milho.

Santos et al. (2011) relataram que a fécula de mandioca a $2 \%$ resultou na melhoria da aparência de mangas cv.Tomy Atkins durante o armazenamento por 21 dias a $12 \pm 0,60 \mathrm{C}$. Moreira et al. (2017), também verificaram que independente da concentração do revestimentoà base de fécula de mandioca e amido de milho houve melhoria da aparência de pimentões cv. Magali após 12 dias de armazenamento, ratificando o observado neste trabalho.

Observa-se na Figura 9, que a incidência de podridões foi observada a partir do nono dia de armazenamento motivada, possivelmente, pelos distúrbios fisiológicos do processo de maturação dos frutos tais como perda de água, redução de firmeza, aumento da atividade respiratória, dentre outros.

Figura 9. Incidência de podridões em tomates de mesa revestidos com diferentes revestimentos e armazenados à temperatura ambiente $\left(25 \pm 2^{\circ} \mathrm{C}\right.$ e $85 \pm 5 \%$ de U. R) por 12 dias. Letras minúsculas (dias de armazenamento) e maiúsculas (tratamentos) não diferem entre si pelo teste de Tukey ao nível de $5 \%$ de probabilidade.

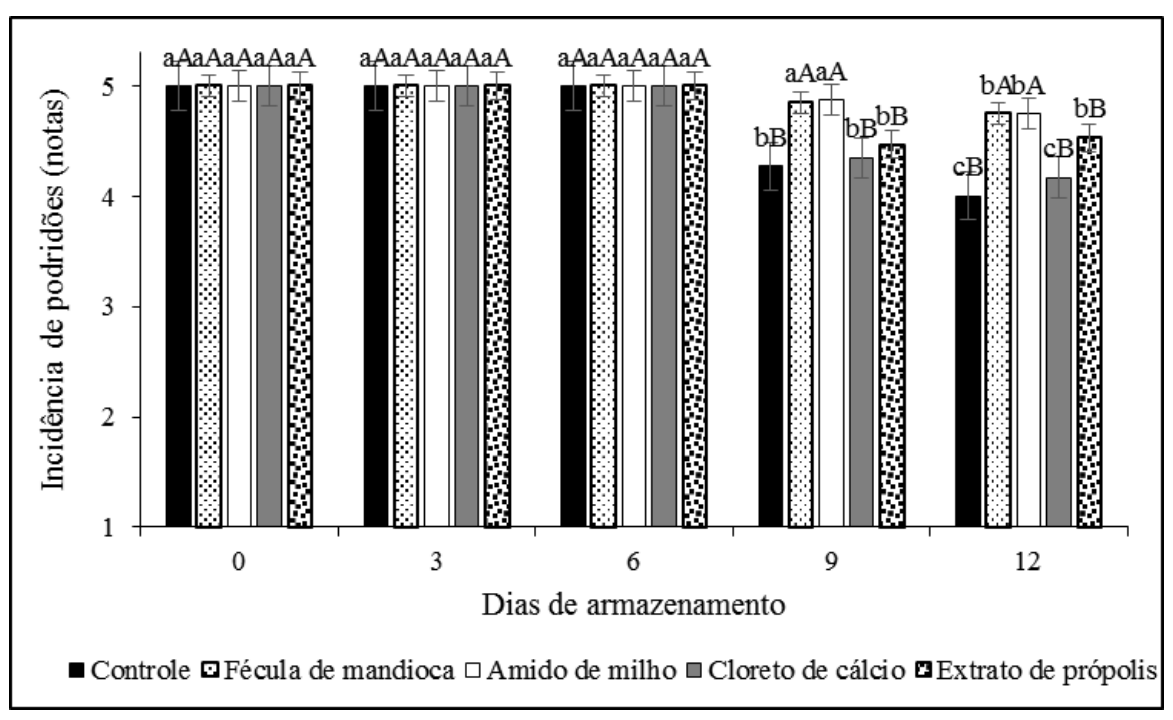


No entanto, verifica-se que a nota média ficou acima de 4,0 (até $5 \%$ de podridões) em todos os tratamentos indicando baixa incidência mesmo com os frutos mantidos sob temperatura ambiente. As etapas de lavagem, sanitização em solução clorada, higienização da bancada de armazenamento podem ter contribuído como fatores externos nessa baixa incidência de podridão.

De modo geral, os tomates revestidos com fécula de mandioca e amido de milho não diferiram entre si $(p<0,05)$ durante todo $o$ período de armazenamento, apresentando notas médias significativamente superior aos frutos dos tratamentos controle, cloreto de cálcioe extrato de própolis (Figura 9). O estádio de maturação mais avançado desses frutos pode ter influenciado essa diferença no terço final de armazenamento.

Na Figura 10, pode-se observar a análise de componentes principais (ACP) realizada, levando em consideração todos os parâmetros de qualidade aqui avaliados, com a média durante os 12 dias de armazenamento. A análise realizada explica, nos dois eixos CP1 e CP2 88,93\% da variância indicando forte correlação entre as variáveis avaliadas com os tratamentos. Godinho (2014),verificouvariância de $80,14 \%$ sobre as variáveis avaliadas em cerejas tratadas com diferentes revestimentos, próximo ao observado neste trabalho.

Figura 10. Análise de componentes principais em tomates de mesa revestidos com diferentes e armazenados à temperatura ambiente $\left(25 \pm 2^{\circ} \mathrm{C}\right.$ e $85 \pm 5 \%$ de $U$. R) por 12 dias. $A M=$ amido de milho; $F M=$ fécula de mandioca; $\mathrm{EP}=$ extrato de própolis; $\mathrm{CaCl}_{2}=$ cloreto de cálcio.

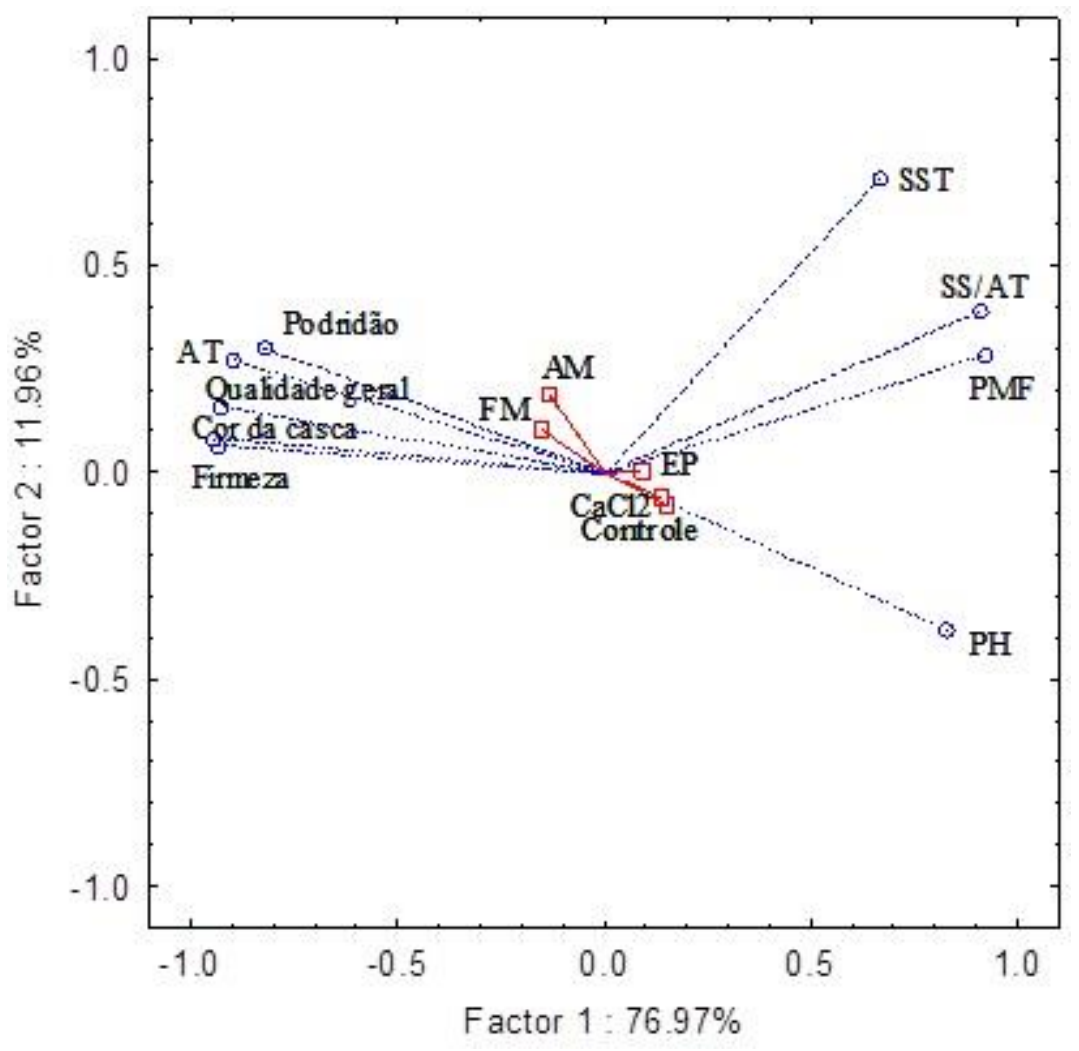

De acordo com a Figura 10, observa-se que as variáveis: incidência de podridões, acidez total titulável, qualidade geral, coloração da casca e firmeza encontram-se fortemente correlacionadas uma vez que formam ângulos entre seus vetores menores que $45^{\circ}$.

Os tratamentos controle, cloreto de cálcio e extrato de própolis encontram-se localizados bem próximo ao eixo $X$ em sentido oposto a projeção das variáveis, com exceção do $\mathrm{pH}$, evidenciando que foram negativamente influenciados com $o$ processo de amadurecimento dos frutos, fato este também observado neste trabalho (Figura 10).

\section{CONCLUSÃO}

Os revestimentos com fécula de mandioca e amido de milho reduziram a 
atividade metabólica dos frutos sendo, portanto, indicados como alternativas para a manutenção da qualidade de tomates de mesa quando mantidos em condição de temperatura ambiente comumente encontrado nos locais de venda a varejo dos frutos.

\section{REFERÊNCIAS}

AOAC. Official methods of analysis of the Association of Official Analytical Chemistry.Washington: AOAC, 2012.

ASSIS, O. B. G.; BRITTO, D. Revisão: coberturas comestíveis protetoras em frutas: fundamentos e aplicações. Braz. J. Food Technol, Campinas, v.7, n.2, p.87-97, 2014.http://dx.doi.org/10.1590/bjft.2014.019

BARBOSA, J. A.; RIBEIRO, W. S.; ALMEIDA, E. I. B. Levantamento das perdas pós-colheitas de frutos, hortaliças e flores no estado da Paraíba. Brasília: Editora Kiron, 2012. 297 p.

CHITARRA, M. I. F.; CHITARRA, A. B. Pós-Colheita de frutas e hortaliças. Fisiologia e manuseio. 2. ed.Lavras: UFLA, 2005. 785p.

CHIUMARELLI, M.; FERREIRA, M. D. Qualidade pós-colheita de tomates 'Débora' com utilização de diferentes coberturas comestíveis e temperaturas de armazenamento. Horticultura Brasileira, Brasília, v.24, n.3, p.381-385, 2006.https://doi.org/10.1590/S0102$\underline{05362006000300023}$

COSTA, T. L. E.; OLIVEIRA, T. A.; SANTOS, F. K. G.; AROUCHA, E. M. M.; LIMA LEITE, R. H. L. Avaliação de coberturas comestíveis compostas por quitosana e argila no revestimento em tomates sob refrigeração pelo método dipping. Revista Verde, Mossoró,v.7, n.5, p.12-19, 2012.

DIEESE.A produção mundial e brasileira de tomate. Goiás: DIEESE, 2010.

EVANGELISTA, R. M.; MENDES, A. S. G.; CORRÊA, C. V; CARDOSO, A. I. I. Uso de películas comestíveis e gelatina na conservação de frutos de mini tomate orgânico 'sweetgrape'. Revista Iberoamericana de TecnologíaPostcosecha, México, v.15, n.2, p.168-176, 2014.
FERRAZ, E. O.; EVANGELISTA, R. M.; CLÁUDIO, M. T. R.; SOARES, L. P. R.; SILVA, B. L.; CARDOSO, A. I. I. Características físico-químicas em tomates cereja tipo SweetGrape envolvidos por diferentes películas protetoras. Horticultura Brasileira, Brasília, v.30, n.2, p.7115-7122, 2012.

FERREIRA, L. B.; DUARTE, A. B.; MARTINS, J. C.; SILVA, N. P.; MIZOBUTSI, G. P. Influência do revestimento de fécula de mandioca em tomate cereja. In: CONGRESSO BRASILEIRO DE PROCESSAMENTO MÍNIMO E PÓS-COLHEITA DE FRUTAS, FLORES E HORTALIÇAS, 1, 2015, Aracaju. Anais. Aracaju: $7 p$.

FERREIRA, S. M. R.; QUADROS, D. A.; KARKLE, E. N. L.; LIMA, J. J.; TULLIO, L. T.; FREITAS, R. J. S. Qualidade pós-colheita do tomate de mesa convencional e orgânico. Ciência e Tecnologia de Alimentos, Campinas, v.30, n.4, p.858-864, 2010.https://doi.org/10.1590/S010120612010000400004

GODINHO, A. C. M. Revestimentos comestíveis bioativos com extrato de carqueja: Aplicação na conservação pós-colheita da cereja. 2014. 115 p. Dissertação (Mestrado) - Universidade de Lisboa, Lisboa-PT, 2014.

JUNG, G.; DEGENHARDT, R. Polímero de recobrimento bioativo à base de amido de milho para prolongamento da vida de prateleira de tomate tipo cereja. Jornada Integrada em Biologia, p. 67-74, jul. 2016. Disponível em: <http://editora.unoesc.edu.br/index.php/iornada integradaembiologia/article/view/10202/5576>.A cessoem: 17 mar. 2017.

KADER, A. A.; ROLLE, R. S.The role of postharvest management in assuring the quality and safety of horticultural produce.FAO Agric. Serv. Bull.,Rome, v.152, p.51, 2004.

KAMEYAMA, O.; ABRÃO JÚNIOR, J.; TEIXEIRA, J. M. A.; ANDRADE, N. J.; MININ, V. P. R.; SOARES, L. S. Extrato de própolis na sanitização e conservação de cenoura. Revista Ceres, Viçosa, v.55, n.3, p.218-223, 2008.

LUNGUINHO, F. S.; SANTOS, A. F.; BEZERRA, J. M.; VIEIRA, M. S. Avaliação não destrutiva na conservação de goiaba 'Paluma' com o uso de embalagens modificadas. Revista Verde, Pombal, v.9, n.5, p.40-50, 2014. 
LUVIELMO, M. M.; LAMAS, S. V. Revestimentos comestíveis em frutas. Estudos Tecnológicos em Engenharia, v.8, n.1, p. 8-15, 2012.http://dx.doi: 10.4013/ete.2012.81.02

MELO,N. C.; SOUZA, L. C.; SILVA, V. F.; GOMES, R. F.; NETO, C. F. O.; COSTA, L. P. C. Cultivo de tomate (SolanumLycopersicum) hidropônico sob diferentes níveis de fósforo e potássio em solução nutritiva. Agroecossistemas, v.6, n.1, p.10-16,

2014. http://dx.doi.org/10.18542/ragros.v6i1.18 45https://doi.org/10.18542/ragros.v6i1.1845

MELO, C. L.; SPOHR, G. M.; QUADROS, C. S.; FIDALSKI, G.; JUNIOR, F. R.S. M.; MELLO, J. M. M.; DALCANTON, F. Aplicação de Recobrimento de Fécula de Batata para a Conservação de Tomates. Revista Tecnológica, Maringá, v.25, n.1, p.103117, 2016.

MONTIBELLER, M. J.; ZAPAROLLI, F. B.; OLIVEIRA, B. G.; PIETROWSKI, G. A. M.; ALMEIDA, D. M. Efeito de filmes de polímeros naturais na conservação de banana cv. Caturra (Musa paradisiaca L.). Revista Brasileira de Produtos Agroindustriais, Campina Grande, v.18, n.1, p.1119, 2016.https://doi.org/10.15871/15178595/rbpa.v18n1p11-19

MOREIRA, E. G. S.; SANCHES, A. G.; SILVA, M. B.; COSTA, J. M.; COSME, S. S.; CORDEIRO, C. A. M. Utilização de filme comestível na conservação pós-colheita do pimentão 'Magali'.Sci. Agrar. Parana.,Marechal Cândido Rondon, v.16, n.1, p.120-126,

2017.http://dx.doi.org/10.18188/19831471/sap.v16n1p120-126

OLIVEIRA, T. A.; LEITE, R. H. L.; AROUCHA, E. M. M.; FERREIRA, R. M. A. Efeito do revestimento de tomate com biofilme na aparência e perda de massa durante o armazenamento. Revista Verde, Mossoró, v.6, n.1, p.230-234, 2011.

OLIVEIRA, C. M.; CONEGLIAN, R. C. C.; CARMO, M. G. F. Conservação pós-colheita de tomate cereja revestidos com película de fécula de mandioca. Horticultura Brasileira, Vitoria da Conquista, v.33, n.4, p.471479,2015.http://dx.doi.org/10.1590/S0102$\underline{053620150000400011}$
PASTOR, C.; SÁNCHEZ-GONZÁLEZ, L.; CHÁFER, M.; CHIRALT, A.; GONZÁlEZ MARTínEZ, C. Physical and antifungal properties of hydroxypropylmethylcellulose based films containing própolis as affected by moisture content. CarbohydratePolymers, Barking,v.82, n.4, p.1174-1183, 2010.https://doi.org/10.1016/j.carbpol.2010.06.0 51

QUEIROZ, V. A. V.; MORAES, E. A.; QUEIROZ, L. R.; TARDIN, F. D.; GUEDES, E. O.; PEREIRA FILHO, I. A.; LOMBARDI, C. T. Utilização de cobertura comestível na conservação pós-colheita de minimilho minimamente processado. Ciênc. Tecnol. Aliment.,Campinas, v.30, n.4, p. 910-916, 2010.

ROSA, C. L. S.; SOARES, A. G.; FREITAS, D. G. C.; ROCHA, M. C.; FERREIRA, J. C. S.; GODOY, R. L. O. Caracterização físico-química, nutricional e instrumental de quatro acessos de tomate italiano (LycopersicumesculentumMill) do tipo 'Heirloom' produzido sob manejo orgânico para elaboração de polpa concentrada. Alim. Nutr., Araraquara, v.22, n.4, p.649-656, 2011.

SANTOS, A. E. O.; ASSIS, V. S.; BEBERT, P.A.; SANTOS, O. O.; BATISTA, F. P.; GRAVINA, G. A. Influência de biofilmes de fécula de mandioca e amido de milho na qualidade pós-colheita de mangas 'Tommy Atkins'. Revista Brasileira de Ciências Agrárias, Recife, v.6, n.3, p.508-513, 2011a.https://doi.org/10.5039/agraria.v6i3a755

SANTOS, A. F.; SILVA, F. V. G.; LOPES, M. F.; VIEIRA, M. M. S.; BEZERRA, J. M. Uso de Biofilmes Comestíveis na Conservação Pós colheita de Tomates e Pimentões. Revista Verde, Mossoró, v.6, n.5, p.146-153, 2011b.

SARMENTO, D. H. A.; SOUZA, P. A.; SARMENTO, J. D. A.; FREITAS, R. V. S.; FILHO, M. S. Armazenamento de Banana 'Prata Catarina' sob Temperatura Ambiente Recobertas com Fécula de Mandioca e PVC. Revista Caatinga, Mossoró, v.28, n.2, p.235-241, 2015.

SCHWARZ, K.; RESENDE, J. T. V.; PRECZENHAK, A. P.; PAULA, J. T.; FARIA, M. V.; DIAS, D. M. Desempenho agronômico e qualidade físicoquímica de híbridos de tomateiro em cultivo rasteiro. Horticultura Brasileira, Brasília, v.31, n.3, 
2013.https://doi.org/10.1590/S0102$\underline{05362013000300011}$

SILVA NETO, W. A. da. Relação de longo prazo entre os preços do tomate nos estados de São Paulo E Goiás. Informações Econômicas, São Paulo, v.44, n.2, p.17-22,2014.

SILVA, A. M.; AMBRÓSIO, M.; NASCIMENTO, D. S.; ALBUQUERQUE, A. N.; KRAUSE, W. Conservação pós-colheita de banana 'maçã' com revestimento comestível a base de fécula de mandioca. AGRARIAN ACADEMY, Centro CientíficoConhecer, Goiânia, v.2, n.3, p.24-34, 2015.

SILVA, F. A. S.; AZEVEDO, C. A. V. Comparison of means of agricultural experimentation data through different tests using the software Assistat.Afr. J. Agric. Res.,v. 11, n. 37, p. 35273531, 2016. https://doi.org/10.5897/AJAR2016.11523

SOUSA, C. M. G.; AROUCHA, E. M. M.; FERREIRA, R. M. A.; LEITE, R. H. L.; OLIVEIRA, T. A.; AMARIZ, A.; GRANJEIRO, L. C. Avaliação da perda de massa e coloração de casca de tomates revestidos com biofilme a base de colágeno durante 0 armazenamento. Horticultura Brasileira, Brasília,v.28, n.2, p.4054-4058, 2010.

SOUZA, P. A.; AROUCHA, E. M. M.; SOUZA, A. E. D.; COSTA, A. R. F. C.; FERREIRA, G. S.; NETO, F. B.Conservação pós-colheita de berinjela com revestimentos de fécula de mandioca ou filme de PVC. Horticultura Brasileira, Brasília, v.27, n.2, p.235-239, 2009.

STATSOFT INC. Programa computacional Statistica 7.0. New York: USA, 2004.https://doi.org/10.1590/S010205362009000200020

VIEIRA, E. L.; PEREIRA, M. E. C.; SANTOS, D. B.; LIMA, M. A. C. Aplicação de biofilmes na qualidade da manga 'Tommy Atkins'. Magistra, Cruz das Almas, v.21, n.3, p.165-170, 2009.

YAMAMOTO, E. L. M.; FERREIRA, R. M. de A.; FERNANDES, P. L. de O.; ALBUQUERQUE, L. B.; ALVES, E. O. Função do Cálcio na Degradação da Parede Celular Vegetal de Frutos. Revista Verde, Mossoró, v.6, n.2, p.49-55, 2011.
Recebido para publicação em 26/08/2017

Revisado em 13/10/2017

Aceito em 18/11/2017 